\title{
Students' Computer Literacy and Academic Performance
}

\author{
Alona Medalia Cadiz-Gabejan ${ }^{1}$ 8(D) $\triangle$ and Melinda Jr C. Takenaka ${ }^{2}$ (D), \\ ${ }^{7}$ Assistant Professor II, Samar State University, Philippines \\ ${ }^{2}$ Senior High School Teacher I, Department of Education, Philippines \\ $\checkmark$ Corresponding Author: Alona Medalia Cadiz-Gabejan, E-mail: alonamedalia.gabejan@ssu.edu.ph
}

\section{ARTICLE INFORMATION}

Received: May 11, 2021

Accepted: June 23, 2021

Volume: 3

Issue: 6

DOI: $10.32996 /$ jweep.2021.3.6.4

\section{KEYWORDS}

Computer literacy, Computer education, Academic performance

\section{ABSTRACT}

This study determined the level of computer literacy and its influence on the academic performance of junior high school students. Specifically, it probed into the students' attitude toward computers and sought answers to the following: the extent of students' computer literacy in terms of Word Processing, Spreadsheet, Presentation, and General Computing; their academic performance based on the mean percentage scores during the first and second quarters of the school year 20192020; issues and problems encountered by them relative to the extent of their computer literacy; and the solutions that may be suggested by themselves to address the constraints they encountered relative to the extent of their computer literacy. Also, by employing descriptive-correlational analysis, the study examined the significant differences in the extent of students' computer literacy in said areas when paired according to their attitude toward computers and the significant relationship between their academic performance and the extent of their computer literacy in terms of the identified areas. Generally, the findings of the study revealed that the students needed to enhance the extent of their computer literacy in the areas of word processing, spreadsheet, presentation, and general computing. The results also signified that the greater the extent of their computer literacy in said areas, the higher their academic performance. This implied that classroom intervention activities are imperative to enhance the extent of the students' computer literacy. Thus, teachers should support them by implementing an intervention program that improves students' level of computer literacy in the specific areas mentioned.

\section{Introduction}

Today, computers play a significant role in all activities and aspects of living in society, as if it is indispensable in all its endeavours - business, education, and personal life. Computers affect every facet of our lives and every sector of the global society; thus, it is essential for anyone who expects to integrate into the 21 st-century society.

According to Cohen (2010), computer literacy is imperative for every individual, particularly for the students. Reynolds (2008) defined computer literacy as being knowledgeable about hardware and software capabilities and understanding how computers and the internet can enhance students' educational experiences. It is the basic understanding of operating computers and similar technology, such as tablets and smartphones. Hence, being computer literate gives a learner an opportunity to cope up with the rapidly changing environment in technology.

Many people, especially those who did not grow up immersed in technology, have trouble understanding the systems necessary for computer literacy. Though not always obvious to people with an intuitive understanding of how to use computers, computer usage requires problem-solving skills, the ability to process text and symbols, and the development of various technical and cognitive skills. There was once a time when computer skills were an optional skill set. Computer literacy is a mandatory skill for success in school, the job force, and everyday life (MathGenie, 2018).

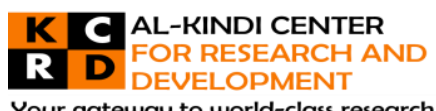

Your gateway to world-class research

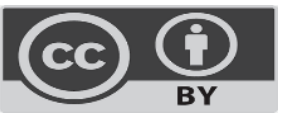

Published by Al-Kindi Center for Research and Development. Copyright (c) the author(s). This open access article is distributed under a Creative Commons Attribution (CC-BY) 4.0 license 
Though modern children are often considered to be "digital natives," certain familial norms and socioeconomic factors can affect a child's ability to learn age-appropriate computer literacy. Laptops and tablets are increasingly used in schools, and computer skills are becoming more and more of an educational necessity among $\mathrm{K}$ to 12 students, reflecting their necessity in the world beyond school (Mbaeze, Ukwandu, \& Anugu, 2010). Students who do not learn age-appropriate computer skills such as typing, online researching, and discerning internet usage can fall behind in their classes and struggle to maintain their grades. Such difficulties can even continue until adulthood (MathGenie, 2018).

There are many levels of computer literacy, ranging from basic computer usage to advanced programming, and one may not realize that his child has fallen behind. To ensure one has a grasp of basic computer literacy, ensure that he is capable of the following: turning a computer on and off, using an operating system, operating software applications, using the internet, and navigating a computer using menus and search functionality (Leonard, 2019). Accordingly, computer competency is a process whereby a student demonstrates his ability to perform school-level basic computing work. In order to prove basic computer competence, a student must demonstrate proficiency in Microsoft Word, Excel, PowerPoint and basic computing.

In support to this, the Department of Education (DepEd) implements the DepEd Internet Connectivity Project (DICP) pursuant to DepEd Order Number 50, series of 2009, first among secondary schools and, later on, extended to the elementary level in consonance with the DepEd Computerization Program (DCP) of DepEd Order No. 78, s. 2010 (Department of Education, 2011). Through this program and the combined efforts of both government and private agencies, e-classrooms had been provided to elementary schools and integrated Information and Communication Technology (ICT) in the school system to raise the ICT literacy of learners and reduce the computer backlog in public schools. Therefore, this demands computer literacy among students.

Lessons in school are technology-based, that the demand for computer literacy among students is high. About 95 percent of the students are computer literate; however, with the advent of blended learning in the new normal, new platforms had been introduced which gave the students difficulty to use and cope with its complicated features in order to successfully submit their outputs online, lagging them behind the scheduled submission or completion. In Silanga National High School (SNHS), under the District of Catbalogan VIII, the demand for computer literacy is also exigent among junior high school students as the aforementioned program is being implemented to enhance the teaching-learning process.

For the past three school years, the junior high school students manifested average performance based on their mean performance scores (MPSs) of 78.11 in S.Y. 2016-2017, 77.34 in S.Y. 2017-2018 77.49 percent in S.Y. 2018-2019. Although the MPSs surpassed the passing rate of 75.00 percent, these are below the mastery level of 85.00 percent which implies that students need improvement in their academic performance. Aitokhuehi and Ojogho (2014) affirmed that computer literate students perform better than non-computer literate in their academic activities. Furthermore, Jarvis and Pastuszka (2008) stressed that computer literacy plays a vital role in students' academic achievement and they need to be computer competent and proficient to be able to operate efficiently in academic contexts. Hence, the researcher contended that it is essential that junior high school students in SNHS enhance their computer literacy so as to improve their academic performance.

Premised on the foregoing situation, the researcher was motivated to conduct this study in order to determine the extent of computer literacy among Grade 10 students and its influence on their academic performance. Therefore, it was hoped that the findings of the study would draw implications to enhance the competence of the students, which would also redound to the enhancement of their academic performance.

\subsection{Research Questions}

This study determined the level of computer literacy and its influence on the academic performance of Grade 10 students in Silanga National High School under the District of Catbalogan VIII, Schools Division of Catbalogan City, during the School Year 2019-2020.

This study determined the level of computer literacy and its influence on the academic performance of Grade 10 students in Silanga National High School under the District of Catbalogan VIII, Schools Division of Catbalogan City, during the School Year 2019-2020.

Specifically, it sought answers to the following questions:

1. What is the attitude of the student-respondents toward the use of the computer?

2. What is the extent of computer literacy of the student-respondents in terms of the following areas, namely:

2.1. Word Processing;

2.2. Spreadsheet;

2.3. Presentation; and 


\subsection{General Computing?}

3. Are there significant differences in the extent of computer literacy of the student-respondents in terms of the foregoing areas when paired according to their attitude toward the use of computer?

4. What is the academic performance of the student-respondents based on the mean percentage score during the first and second quarters?

5. Is there a significant relationship between the academic performance of the student-respondents based on the mean percentage score during the first and second quarters and the extent of their computer literacy in terms of the identified areas?

6. What are the issues and problems encountered by the student-respondents relative to the extent of their computer literacy?

7. What solutions may the student-respondents suggest to address the constraints they encountered relative to the extent of their computer literacy?

\section{Material and Methods}

\subsection{Research Design}

This study employed the descriptive-correlation research design using the questionnaire as the main instrument. It described the attitude of the student-respondents toward the use of computers and elicited the extent of their computer literacy in terms of Word Processing, Spreadsheet, Presentation, and General Computing which were compared for any significant variations when paired according to their attitude toward the computer. Issues and problems encountered by the student-respondents were also determined and the solutions suggested by them to address the problems encountered. Moreover, the study was correlational, considering that the academic performance of the student-respondents based on the Mean Percentage Score during the first and second quarters was associated with the extent of their computer literacy in terms of the identified areas for any significant linear relationship.

\subsection{Instrumentation}

This study utilized the questionnaire and the school forms in collating relevant information exigent to this study.

2.2.1. Questionnaire. Questionnaire. The researcher developed a questionnaire intended for the student-respondents which was composed of four parts. Part I was designed to appraise their attitude toward the computer. It contained 10 attitude statements which were agreed or disagreed by them using the Five-point Likert Scale as follows: 5 for Strongly Agree (SA), 4 for Agree (A), 3 for Uncertain (U), 2 for Disagree (D), and 1 for Strongly Disagree (SD).

Part II determined the extent of computer literacy of the student-respondents in terms of Word Processing, Spreadsheet, Presentation, and General Computing. It contained 51 indicators whereby they assessed their computer literacy using the following Five-point Thurstone Scale, viz: 5 for Extremely Literate (EL), 4 for Highly Literate (HL), 3 for Moderately Literate (ML), 2 for Slightly Literate (SL) and Not Literate (NL). Part III solicited the issues and problems encountered by the student-respondents relative to computer literacy. From the pre-identified issues and problems, they assessed each item using the Five-point Thurstone Scale as follows: 5 for Extremely (E), 4 for Highly (H), 3 for Moderately (M), 2 for Slightly (S), and 1 for Never (N).

Part IV elicited the solutions suggested by the student-respondents to address the problems they encountered relative to their computer literacy in terms of the identified areas. From the pre-listed solutions, they assessed the appropriateness of each item using the Five-point Thurstone Scale as follows: 5 for Extremely a Solution (ES), 4 for Highly a Solution (HS), 3 for Moderately a Solution (MS), 2 for Slightly a Solution (SS), and 1 for Not a Solution (NS).

The questionnaire underwent expert validation focusing on face, content, construct, pragmatic, and convergent-discriminant validity with consideration of the student-respondents' cognitive and situational perspectives.

2.2.2 School Forms. The school forms, through document analysis, were the source for the academic performance of the student-respondents based on the first and second quarters.

\subsection{Sampling Procedure}

This study utilized two-stage sampling in choosing the student-respondents. The First Stage was the determination of the number of the student-respondents using the Slovin's formula (Sevilla et al., 1992). From the sample size, a stratified sampling procedure was applied with equal probability. More or less, the student-respondents per track or section were the same in number. Of the 322 Grade-10 students during the ensuing school year, 178 or 55.28 percent served as respondents of the study. 
The Second Stage was the identification of the student-respondents. The systematic sampling with replacement was utilized. That is, every fifth student in the register of enrollees was invited for an interview. If and when the fifth student from the last interviewed one was available or absent during the time of data collection, the sampling continued following the same system until the total number of student-respondents were completed for every school.

\subsection{Data Gathering Procedure}

Before the conduct of the study, the researcher sought authorization from the concerned officials. Because of the community quarantines and other strict health protocols implemented by the local Inter-Agency Task Force (IATF) amid the COVID-19 pandemic, the researcher had a hard time retrieving the questionnaires from the student-respondents which caused the delays because she had to wait until community lockdown would be lifted and she also had to observe said health protocols. Data generation lasted for about two months, including travel time. Thereafter, manual editing and coding followed as a means to check the consistency of the information in preparation for the data analysis.

\subsection{Statistical Treatment of Data}

To give meaning to the data that were collected, descriptive statistical tools were employed, namely: Frequency Count, Percentage, Arithmetic Mean, Standard Deviation, Weighted Mean, One-Way ANOVA, Tukey's Test, Pearson's Product-Moment Coefficient of Correlation, and the Fisher's t-Test. In testing the hypotheses, the decision whether the null hypothesis was accepted or rejected, the following decision rule served as a guide: accept the null hypothesis if and when the computed value turned lesser than the critical or tabular value or the $p$-value turned greater than the $\alpha$; on the other hand, reject the null hypothesis if and when the computed value turned equal or greater than the critical or tabular value or the $p$-value turned equal or lesser than the $\alpha$. The hypotheses testing assumed that the level of significance would equal to $\alpha=0.05$ in a two-tailed test. Available statistical software or packages were utilized for the accuracy and precision in the data processing.

\section{Results and Discussion}

\subsection{Attitude Toward Computer}

Table 1 appraises the attitude of the student-respondents toward the computer. Ten attitude statements were identified in this area whereby the respondents signified their agreement or disagreement on each statement.

\section{Table 1: Attitude Toward Computer of Student-Respondents}

\begin{tabular}{|c|c|c|c|c|}
\hline \multicolumn{3}{|c|}{ Attitude Statement } & $\begin{array}{l}\text { Weighted } \\
\text { Mean }\end{array}$ & Interpretation \\
\hline \multicolumn{3}{|c|}{ 1. I am interested in learning about computer. } & 4.19 & A \\
\hline \multicolumn{3}{|c|}{ 2. I believe computer can make my studies easier. } & 4.14 & A \\
\hline \multicolumn{3}{|c|}{ 3. I am enthusiastic in using computer in my studies. } & 3.68 & A \\
\hline \multicolumn{3}{|c|}{ 4. I like exploring things through the use of computer. } & 4.08 & A \\
\hline \multicolumn{3}{|c|}{ 5. Computer facilitates my research and learning. } & 4.19 & A \\
\hline \multicolumn{3}{|c|}{ 6. Eventually, the use of computer improves my academic performance. } & 3.96 & A \\
\hline \multicolumn{3}{|c|}{ 7. I can learn many things through using computer. } & 4.06 & A \\
\hline \multicolumn{3}{|c|}{$\begin{array}{l}\text { 8. I feel more fulfilled by being knowledgeable with computer and its } \\
\text { operation. }\end{array}$} & 3.81 & A \\
\hline \multirow{2}{*}{\multicolumn{3}{|c|}{$\begin{array}{l}\text { 9. I desire to use computer in every tasks I have in school. } \\
\text { 10. Using computer allows me to be innovative and makes me more } \\
\text { output-oriented. }\end{array}$}} & 3.74 & A \\
\hline & & & 3.90 & $A$ \\
\hline \multicolumn{3}{|c|}{ Grand Weighted Mean } & \multicolumn{2}{|c|}{3.98} \\
\hline \multicolumn{3}{|c|}{ Interpretation } & \multicolumn{2}{|c|}{ Agree } \\
\hline $4.51-5.00$ & Strongly Agree & (SA) & & \\
\hline $3.51-4.50$ & Agree & (A) & & \\
\hline $2.51-3.50$ & Uncertain & $(U)$ & & \\
\hline $1.51-2.50$ & Disagree & (D) & & \\
\hline $1.00-1.50$ & Strongly Disagree & (SD) & & \\
\hline
\end{tabular}

From the table, it can be gleaned that the student-respondents "agreed" all the identified attitude statements depicting their attitude toward computer with weighted means ranging from 3.68 to 4.19 . The first two attitude statements that equally obtained the highest weighted mean corresponded to the following: "I am interested in learning about computer" and 
"computer facilitates my research and learning." On the other hand, the attitude statement obtained the least weighted mean corresponding to the statement stating, "I am enthusiastic in using computer in my studies."

Taken as a whole, the student-respondents "agreed" their attitude toward computer being indicated by the grand weighted means of 3.98. This signified that the student-respondents showed a highly favorable attitude toward computers, which implied their interest in learning it.

\subsection{Extent of Computer Literacy of Student-Respondents}

This part shows the extent of computer literacy of student-respondents in the areas of Word Processing, Spreadsheet, Presentation and General Computing.

3.2.1. Word Processing. Table 2 discloses the extent of computer literacy of the student-respondents in the area of Word Processing. There were 11 identified indicators included in this area to deduce the students' computer literacy in word processing.

Table 2: Extent of Computer Literacy of Student-Respondents in Terms of Word Processing

\begin{tabular}{|c|c|c|c|c|c|}
\hline & \multicolumn{3}{|c|}{ Indicator } & $\begin{array}{c}\text { Weighted } \\
\text { Mean }\end{array}$ & Interpretation \\
\hline & \multicolumn{3}{|c|}{ 1. To create and delete documents } & 3.30 & ML \\
\hline & \multicolumn{3}{|c|}{ 2. To manipulate text in a Word document } & 3.29 & $M L$ \\
\hline & \multicolumn{3}{|c|}{ 3. To copy and paste objects in a Word document } & 3.80 & $\mathrm{HL}$ \\
\hline & \multicolumn{3}{|c|}{ 4. To change fonts and font characteristics in Word } & 3.67 & $\mathrm{HL}$ \\
\hline & \multicolumn{3}{|c|}{ 5. To show and hide comments in a Word document } & 3.53 & $\mathrm{HL}$ \\
\hline & \multicolumn{3}{|c|}{ 6. To insert pictures in Word documents } & 3.93 & $\mathrm{HL}$ \\
\hline & \multicolumn{3}{|c|}{$\begin{array}{l}\text { 7. To change page characteristics such as margins and page } \\
\text { orientation in a Word document }\end{array}$} & 3.63 & $\mathrm{HL}$ \\
\hline & \multicolumn{3}{|c|}{ 8. To set print options and print Word documents } & 3.60 & $\mathrm{HL}$ \\
\hline & \multicolumn{3}{|c|}{ 9. To create and insert tables in Word } & 3.57 & $\mathrm{HL}$ \\
\hline & \multicolumn{3}{|c|}{ 10. To set page breaks in Word } & 3.21 & ML \\
\hline & \multicolumn{3}{|c|}{ 11. To open, save, and close documents in Word } & 3.90 & $\mathrm{HL}$ \\
\hline & \multicolumn{3}{|c|}{ Grand Weighted Mean } & \multicolumn{2}{|c|}{3.58} \\
\hline & \multicolumn{3}{|c|}{ Interpretation } & \multicolumn{2}{|c|}{ Highly Literate } \\
\hline Legend: & $4.51-5.00$ & Extremely Literate & $(E L)$ & & \\
\hline & $3.51-4.50$ & Highly Literate & $(\mathrm{HL})$ & & \\
\hline & $2.51-3.50$ & Moderately Literate & $(\mathrm{ML})$ & & \\
\hline & $1.51-2.50$ & Slightly Literate & $(\mathrm{SL})$ & & \\
\hline & $1.00-1.50$ & Not Literate & $(\mathrm{NL})$ & & \\
\hline
\end{tabular}

The table shows that the student-respondents appraised themselves eight indicators along this area as "highly literate" with weighted means ranging from 3.53 to 3.93. The indicators in this case that obtained the highest and the least weighted means, respectively, corresponded to the indicators stating: "to insert pictures in Word documents" and "to show and hide comments in a Word document." The student-respondents appraised the remaining three indicators along this area that they were "moderately literate" on these, which corresponded to the indicators stating: "to create and delete documents," "to manipulate text in a Word document" and "to set page breaks in Word," with weighted means of 3.30, 3.29 and 3.21, respectively.

Taken as a whole, the student-respondents considered themselves "highly literate" along with their computer literacy in the area of word processing, being shown by the grand weighted mean of 3.58. This signified that the student-respondents had the capability to operate and use word processing as a way to facilitate their learning. However, there were areas where the studentrespondents were less competent and needed to be enhanced.

3.2.2. Spreadsheet. Table 3 reveals the extent of computer literacy of the student-respondents in the area of Spreadsheet. There were 20 identified indicators included in this area to deduce the students' computer literacy in the spreadsheet. 
Table 3: Extent of Computer Literacy of Student-Respondents in Terms of Spreadsheet

\begin{tabular}{|c|c|c|c|}
\hline & Indicator & $\begin{array}{c}\text { Weighted } \\
\text { Mean }\end{array}$ & Interpretation \\
\hline 1. & To create a spreadsheet & 2.96 & ML \\
\hline 2. & To know the elements of the Excel screen & 2.77 & ML \\
\hline 3. & To work with text in Excel spreadsheets & 2.78 & ML \\
\hline 4. & work with objects in an Excel spreadsheet & 2.79 & ML \\
\hline 5. & To change font elements in an Excel spreadsheet & 3.10 & ML \\
\hline 6. & To work with comments in an Excel spreadsheet & 3.73 & $\mathrm{HL}$ \\
\hline 7. & To work with pictures in Excel & 2.86 & ML \\
\hline 8. & To change page elements such as orientation and margins in Excel & 2.87 & ML \\
\hline 9. & To print Excel spreadsheets & 2.96 & ML \\
\hline 10. & To insert tables and charts into Excel spreadsheets & 3.03 & ML \\
\hline 11. & To apply different number formats in Excel & 3.02 & ML \\
\hline 12. & To create an IF function and a SUM function in Excel & 2.76 & ML \\
\hline 13. & To merge cells in Excel & 2.76 & ML \\
\hline 14. & To rename worksheets in Excel & 2.96 & ML \\
\hline 15. & To freeze and unfreeze columns and rows in Excel & 2.79 & ML \\
\hline 16. & To check spelling and edit cell contents in Excel & 3.16 & ML \\
\hline 17. & To use the Fill Handle in Excel & 2.91 & ML \\
\hline 18. & To insert and delete rows and columns in an Excel spreadsheet & 2.92 & ML \\
\hline 19. & To track changes in an Excel spreadsheet & 2.78 & ML \\
\hline 20. & To copy and paste formulas in Excel & 2.93 & ML \\
\hline & Grand Weighted Mean & \multicolumn{2}{|c|}{2.94} \\
\hline
\end{tabular}

\section{Interpretation}

Extremely Literate

Highly Literate

Moderately Literate

Slightly Literate

Not Literate

Moderately Literate

\begin{tabular}{llll}
\hline \hline Legend: & $4.51-5.00$ & Extremely Literate & $(\mathrm{EL})$ \\
& $3.51-4.50$ & Highly Literate & $(\mathrm{HL})$ \\
$2.51-3.50$ & Moderately Literate & $(\mathrm{ML})$ \\
& $1.51-2.50$ & Slightly Literate & $(\mathrm{SL})$ \\
$1.00-1.50$ & Not Literate & $(\mathrm{NL})$
\end{tabular}

The table shows that the student-respondents appraised themselves as "highly literate" in one indicator only corresponding to the statement stating, "to work with comments in an Excel spreadsheet" with a weighted mean of 3.73 while as "moderately literate" in the 19 indicators depicting this area with weighted means ranging from 2.78 to 3.10 . The indicator that obtained the highest weighted mean in this case corresponded to the statement stating, "to work with comments in an Excel spreadsheet," while indicators that equally obtained the least weighted mean stated: "to create an IF function and a SUM function in Excel" and "to merge cells in Excel."

Taken as a whole, the student-respondents considered themselves "moderately literate" in the spreadsheet being manifested by the grand weighted mean of 2.94. This signified that they were less competent in this area, which needs to be enhanced through an intervention activity.

3.2.3. Presentation. Table 4 reveals the extent of computer literacy of the student-respondents in the area of Presentation. There were nine identified indicators included in this area to deduce the students' computer literacy in presentation. 
Table 4: Extent of Computer Literacy of Student-Respondents in Terms of Presentation

\begin{tabular}{|c|c|c|c|c|c|}
\hline \multicolumn{4}{|c|}{ Indicator } & $\begin{array}{c}\text { Weighted } \\
\text { Mean }\end{array}$ & Interpretation \\
\hline 1. & \multicolumn{3}{|c|}{ To create and modify a presentation } & 3.40 & ML \\
\hline 2. & \multicolumn{3}{|c|}{ To manipulate slides in PowerPoint } & 3.53 & $\mathrm{HL}$ \\
\hline 3. & \multicolumn{3}{|c|}{ To add WordArt to a presentation } & 3.39 & ML \\
\hline 4. & \multicolumn{3}{|c|}{ To animate different elements of a presentation } & 3.32 & ML \\
\hline 5. & \multicolumn{3}{|c|}{ To insert tables and charts in a PowerPoint slide } & 3.43 & ML \\
\hline 6. & \multicolumn{3}{|c|}{ To insert comments in a PowerPoint presentation } & 3.25 & ML \\
\hline 7. & \multicolumn{3}{|c|}{ To use different views in PowerPoint } & 3.44 & ML \\
\hline 8. & \multicolumn{3}{|c|}{ To modify elements of a presentation such as layout, size, and lists } & 3.38 & ML \\
\hline 9. & \multicolumn{3}{|c|}{ To print slides for a presentation } & 3.42 & ML \\
\hline & \multicolumn{3}{|c|}{ Grand Weighted Mean } & \multicolumn{2}{|c|}{3.26} \\
\hline & \multicolumn{3}{|c|}{ Interpretation } & \multicolumn{2}{|c|}{ Moderately Literate } \\
\hline & $4.51-5.00$ & Extremely Literate & $(E L)$ & & \\
\hline & $1.51-2.50$ & Slightly Literate & $(\mathrm{SL})$ & & \\
\hline & $3.51-4.50$ & Highly Literate & $(\mathrm{HL})$ & & \\
\hline & $1.00-1.50$ & Not Literate & $(\mathrm{NL})$ & & \\
\hline & $2.51-3.50$ & Moderately Literate & $(\mathrm{ML})$ & & \\
\hline
\end{tabular}

The table presents that the student-respondents appraised themselves in one indicator only along this area as "highly literate," which corresponded to the statement stating, "to manipulate slides in PowerPoint," with a weighted mean of 3.53 . The remaining eight indicators considered themselves "moderately literate" with weighted means ranging from 3.23 to 3.44 . The indicators in this case that obtained the highest and the least weighted means, respectively, corresponded to the statements stating: "to use different views in PowerPoint" and "to insert comments in a PowerPoint presentation."

Taken as a whole, the student-respondents appraised themselves as "moderately literate" along with presentation being supported by the grand weighted mean of 3.26. This signified that the student-respondents believed they were still less competent in using presentation to facilitate their studies. Impliedly, they should be assisted to develop this area through an intervention activity.

3.2.4. General Computing. Table 5 reveals the extent of computer literacy of the student-respondents in the area of General Computing. There were 11 identified indicators included in this area to deduce the students' computer literacy in general computing.

The table further reveals that the student-respondents considered themselves "highly literate" in eight indicators along this area, with weighted means ranging from 3.55 to 3.85. In these indicators, the ones that obtained the highest and the least weighted means, respectively, corresponded to the following statements: "to create and delete files and folders" and "to know the details about how files are named" while in the remaining three indicators, the same group of respondents appraised themselves as "moderately literate," which corresponded to the statements, stating: "to work with files in the Recycle Bin," "to identify different types of computers" and "to know the different types of operating systems," with weighted means of 3.33 , 3.25 and 3.09 , respectively.

Table 5: Extent of Computer Literacy of Student-Respondents in Terms of General Computing

\begin{tabular}{ll|cc}
\hline \hline \multicolumn{1}{c|}{ Indicator } & $\begin{array}{c}\text { Weighted } \\
\text { Mean }\end{array}$ & Interpretation \\
\hline 1. To sign in and out of Windows and how to close Windows & 3.78 & $\mathrm{HL}$ \\
2. To manipulate windows (maximize, minimize, close) & 3.67 & $\mathrm{HL}$ \\
3. To start and close Office apps & 3.68 & $\mathrm{HL}$ \\
4. To work with files in the Recycle Bin & 3.33 & $\mathrm{ML}$ \\
5. To create and delete files and folders & 3.85 & $\mathrm{HL}$ \\
6. To identify different types of computers & 3.25 & $\mathrm{ML}$
\end{tabular}




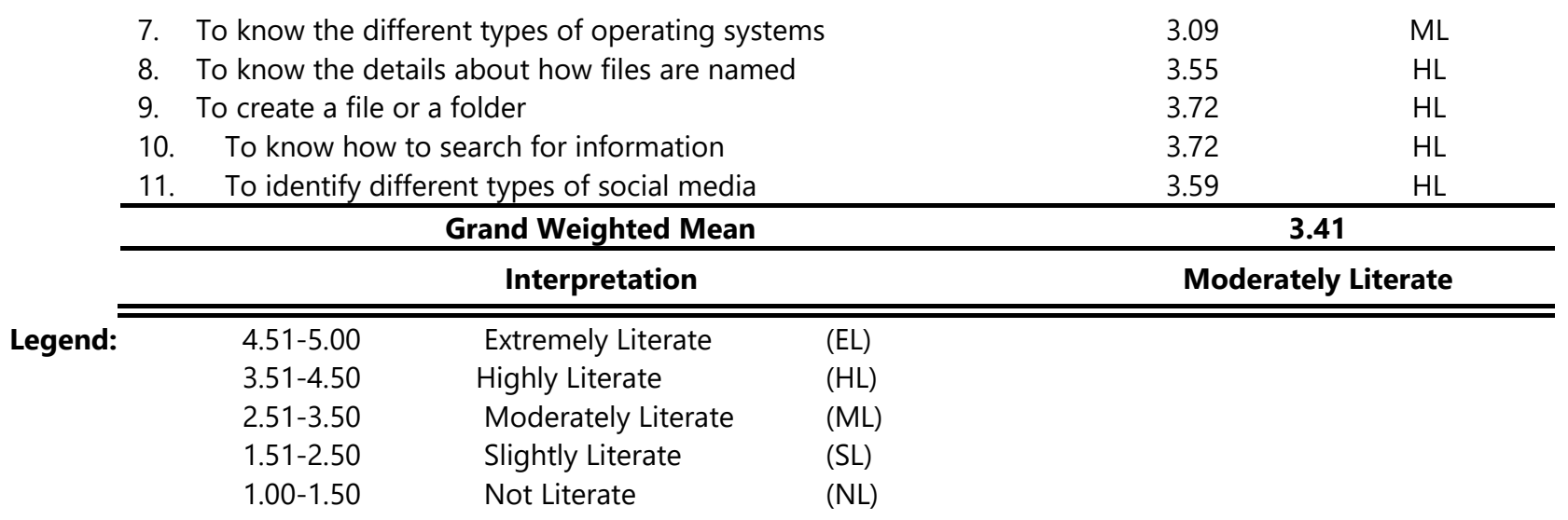

Taken as a whole, the student-respondents evaluated themselves as "moderately literate" along with general computing with a grand weighted mean of 3.41. This indicated that they felt that they still needed to be enhanced in this area of computer literacy. Thus, teachers should support them by providing specific intervention activities, especially hands-on computer activities, to improve their computer literacy in terms of general computing and facilitate their learning in this particular area.

\subsection{Comparison of the Extent of Computer Literacy of the Student-Respondents When Paired According to Their Attitude toward Computer}

This part contains the comparison of the extent of computer literacy of the student-respondents in Word processing, Spreadsheet, Presentation, and General Computing when each is paired according to their attitude toward computer.

3.3.1. Word Processing. Table 6 reveals the comparison of the extent of computer literacy of the student-respondents in Word Processing when paired according to their attitude toward computer.

Table 6: Comparison of the Extent of Computer Literacy of the Student-Respondents in Word Processing When Paired According to Their Attitude toward Computer

\begin{tabular}{|c|c|c|c|c|c|}
\hline \multirow{2}{*}{ Variate } & \multicolumn{2}{|c|}{ F-Value } & \multirow{2}{*}{ df } & \multirow{2}{*}{$\begin{array}{l}\text { P-Value } \\
@ \alpha=.05\end{array}$} & \multirow{2}{*}{$\begin{array}{c}\text { Evaluation/ } \\
\text { Decision }\end{array}$} \\
\hline & Computed & Critical & & & \\
\hline Attitude Toward Computer & 1.678 & 1.530 & $\begin{array}{l}50 \\
48 \\
\end{array}$ & .037 & S / Reject Ho \\
\hline
\end{tabular}

$\mathrm{S}=$ Significant NS = Not Significant

3.3.1.1. Attitude Toward Computer. In the comparison of the extent of computer literacy of the student-respondents in terms of word processing when grouped according to their attitude toward computer using the ANOVA, the computed value was posted at 1.678 with $\mathrm{df}=50$ and 48 and a $p$-value of .037 at $.05 \alpha$. The critical t-value was set at +1.530 . Furthermore, in the evaluation, the computed value was compared with the critical value and the $p$-value was compared with the $\alpha$.

In the comparison of the aforementioned values, it was proven that the computed value turned greater than the critical value and the $p$-value turned lesser than the $\alpha$ thus, the variations among the means were significant which signified that evaluation of the students as regards the extent of their computer literacy in the area of word processing when grouped according to their attitude toward computer was essentially dissimilar denoting that their attitude toward computer matters on the extent of computer literacy in terms of this area. Therefore, the null hypothesis stating that "there is no significant difference on the extent of computer literacy of the student-respondents in terms of word processing when paired according to their attitude toward computer," was rejected.

This signified that the students who had a highly favorable attitude toward computer manifested a higher extent of computer literacy in terms of word processing, which could be attributed to their high interest that they strove to learn every facet of computer operation. 
3.3.2. Spreadsheet. Table 7 contains the comparison of the extent of computer literacy of the student-respondents in Spreadsheet when paired according to their attitude toward computer.

Table 7: Comparison of the Extent of Computer Literacy of the Student-Respondents in Spreadsheet When Paired According to Their Attitude toward Computer

\begin{tabular}{|c|c|c|c|c|c|}
\hline \multirow{2}{*}{ Variate } & \multicolumn{2}{|c|}{ F-Value } & \multirow{2}{*}{ df } & \multirow{2}{*}{$\begin{array}{c}\text { P-Value } \\
@ \\
\alpha=.05 \\
\end{array}$} & \multirow{2}{*}{$\begin{array}{c}\text { Evaluation/ } \\
\text { Decision }\end{array}$} \\
\hline & Computed & Critical & & & \\
\hline Attitude Toward Computer & 1.134 & 1.530 & $\begin{array}{l}53 \\
45\end{array}$ & .335 & NS / Accept Ho \\
\hline
\end{tabular}

$\mathrm{S}=$ Significant $\quad$ NS $=$ Not Significant

3.3.2.1. Attitude Toward Computer. In the comparison of the extent of computer literacy of the student-respondents in terms of spreadsheet when grouped according to their attitude toward computer using the ANOVA, the computed value was posted at 1.134 with $\mathrm{df}=53$ and 45 and a p-value of .335 at $.05 \alpha$. The critical t-value was set at +1.530 . Furthermore, in the evaluation, the computed value was compared with the critical value and the $p$-value was compared with the $\alpha$.

In the comparison of the aforementioned values, it was proven that the computed value turned lesser than the critical value and the $p$-value turned greater than the $\alpha$; thus, the variations among the means were not significant which signified that evaluation of the students as regards the extent of their computer literacy in the area of the spreadsheet when grouped according to their attitude toward computer was essentially similar denoting that irrespective of their interest and attitude toward learning the computer, they have the same extent of computer literacy in terms of this area. Therefore, the null hypothesis stating that "there is no significant difference on the extent of computer literacy of the student-respondents in terms of the spreadsheet when grouped according to their attitude toward computer," was accepted.

3.3.3. Presentation. Table 8 contains the comparison of the extent of computer literacy of the student-respondents in Presentation when paired according to their attitude toward computer.

Table 8: Comparison of the Extent of Computer Literacy of the Student-Respondents in Presentation When Paired According to Their Attitude toward Computer

\begin{tabular}{|c|c|c|c|c|c|}
\hline \multirow{2}{*}{ Variate } & \multicolumn{2}{|c|}{ F-Value } & \multirow{2}{*}{ df } & \multirow{2}{*}{$\begin{array}{c}\text { P-Value } \\
@ \\
\alpha=.05 \\
\end{array}$} & \multirow{2}{*}{$\begin{array}{c}\text { Evaluation/ } \\
\text { Decision }\end{array}$} \\
\hline & Computed & Critical & & & \\
\hline Attitude Toward Computer & 1.443 & 1.500 & $\begin{array}{l}35 \\
63 \\
\end{array}$ & .102 & NS / Accept Ho \\
\hline
\end{tabular}

3.3.3.1. Attitude Toward Computer. In the comparison of the extent of computer literacy of the student-respondents in terms of presentation when grouped according to their attitude toward computer using the ANOVA, the computed value was posted at 1.443 with $\mathrm{df}=35$ and 63 and a p-value of .102 at $.05 \alpha$. The critical t-value was set at +1.500 . Furthermore, in the evaluation, the computed value was compared with the critical value and the $p$-value was compared with the $\alpha$.

In the comparison of the aforementioned values, it was proven that the computed value turned lesser than the critical value and the $p$-value turned greater than the $\alpha$ thus, the variations among the means were not significant which signified that evaluation of the students as regards the extent of their computer literacy in the area of presentation when grouped according to their attitude toward computer was essentially similar denoting that irrespective of their interests and attitude toward computer, they have the same extent of computer literacy in terms of this area. Therefore, the null hypothesis stating that "there is no significant difference on the extent of computer literacy of the student-respondents in terms of presentation when grouped according to their attitude toward computer," was accepted.

3.3.4. General Computing. Table 9 contains the comparison of the extent of computer literacy of the student-respondents in General Computing when paired according to their attitude toward computer. 
Table 9: Comparison of the Extent of Computer Literacy of the Student-Respondents in General Computing When Paired According to Their Attitude toward Computer

\begin{tabular}{|c|c|c|c|c|c|}
\hline \multirow{2}{*}{ Variate } & \multicolumn{2}{|c|}{ F-Value } & \multirow{2}{*}{ df } & \multirow{2}{*}{$\begin{array}{l}\text { P-Value } \\
@ \alpha=.05\end{array}$} & \multirow{2}{*}{$\begin{array}{c}\text { Evaluation/ } \\
\text { Decision }\end{array}$} \\
\hline & Computed & Critical & & & \\
\hline Attitude Toward Computer & 2.653 & 1.500 & $\begin{array}{l}35 \\
63\end{array}$ & .000 & S / Reject Ho \\
\hline
\end{tabular}

$\mathrm{S}=$ Significant $\quad$ NS $=$ Not Significant

3.3.4.1. Attitude Toward Computer. In the comparison of the extent of computer literacy of the student-respondents in terms of general computing when grouped according to their attitude toward computer using the ANOVA, the computed value was posted at 2.653 with $\mathrm{df}=35$ and 63 and a $p$-value of .000 at $.05 \alpha$. The critical t-value was set at +1.500 . Furthermore, in the evaluation, the computed value was compared with the critical value and the $p$-value was compared with the $\alpha$.

In the comparison of the aforementioned values, it was proven that the computed value turned greater than the critical value and the $p$-value turned lesser than the $\alpha$ thus, the variations among the means were significant which signified that evaluation of the students as regards the extent of their computer literacy in the area of general computing when grouped according to their attitude toward computer was essentially dissimilar denoting that their interest and attitude toward computer mattered on the extent of computer literacy in terms of this area. This signified that the students with highly favorable attitudes toward computer manifested a greater extent of computer literacy in the area of presentation than the students who were apathetic to it. Therefore, the null hypothesis stating that, "there is no significant difference on the extent of computer literacy of the studentrespondents in terms of general computing when grouped according to their attitude toward computer," was rejected.

\subsection{Academic Performance of Student-Respondents Based on the Mean Grade of the First and Second Quarters}

Table 10 reveals the academic performance of student-respondents based on the Mean Grade of the first and second quarters.

Table 10: Academic Performance of Student-Respondents Based on the Mean Grade of the First and Second Quarters

\begin{tabular}{c|c|c}
\hline \hline Quarter & Mean & SD \\
\hline First & 84.50 & 3.15 \\
Second & 85.45 & 3.69 \\
\hline Overall & $\mathbf{8 4 . 9 8}$ & $\mathbf{3 . 4 2}$ \\
\hline \hline
\end{tabular}

The table shows that during the first quarter, the student-respondents obtained a Mean Academic Performance of 84.50 with a SD of 3.15 while during the second quarter, they garnered 85.45 with a SD of 3.69. Consequently, the student-respondents' overallMeanAcademicPerformance was posted at 84.98 with a SD of 3.42 .

The foregoing data signified that the student-respondents manifested a favorable performance higher than the required mastery level set by the DepEd which was 75 percent.

3.5. Relationship Between the Academic Performance of the Student-Respondents Based on the Mean Grade of the First and Second Quarters and Their Extent of Computer Literacy

Table 11 contains the relationship between the academic performance of the student-respondents based on the Mean Grade of the first and second quarters and their extent of computer literacy in terms of Word Processing, Spreadsheet, Presentation, and General Computing.

3.5.1. Word Processing. In associating the relationship between the academic performance of the student-respondents based on the Mean Grade of the first and second quarters and their extent of computer literacy in terms of Word Processing using Pearson's $r$, the computed value was posted at .561, denoting a "moderate" linear association. In testing the significance of the noted linear association between the two variables utilizing the Fisher's $\mathrm{t}$-Test, the computed value was posted at 6.709 with $\mathrm{df}=$ 98 and a p-value of .000 at $.05 \alpha$. The critical t-value was set at +1.984 . Furthermore, the computed value was compared with the critical value and the $p$-value was compared with the $\alpha$. 
Table 11: Relationship Between the Academic Performance of the Student-Respondents Based on the Mean Grade of the First and Second Quarters and Their Extent of Computer Literacy

\begin{tabular}{|c|c|c|c|c|c|}
\hline \multirow{2}{*}{ Area } & \multicolumn{2}{|c|}{ Linear Association } & \multirow{2}{*}{$\begin{array}{c}\text { Fisher's t- } \\
\text { Value }\end{array}$} & \multirow{2}{*}{ p-Value } & \multirow{2}{*}{$\begin{array}{c}\text { Evaluation/ } \\
\text { Decision }\end{array}$} \\
\hline & Coeffi-cient & Degree & & & \\
\hline Word Processing & .561 & Moderate & 6.709 & .000 & S / Reject Ho \\
\hline Spreadsheet & .697 & Moderate & 9.622 & .000 & S / Reject Ho \\
\hline Presentation & .732 & Moderate & 10.636 & .000 & S / Reject Ho \\
\hline General Computing & .741 & Moderate & 10.924 & .000 & S / Reject Ho \\
\hline
\end{tabular}

Fisher's t-Critical Value $= \pm 1.984 \quad$ S - Significant

$\mathrm{df}=98 \quad \alpha=.05 \quad$ NS - Not Significant

In the comparison of the aforementioned values, it was proven that the computed value turned greater than the critical value and the $p$-value turned lesser than the $\alpha$. Thus, the linear association between the two variables was significant, signifying that the extent of computer literacy of the students in terms of word processing did significantly influence their academic performance based on the Mean Grade of the first and second quarters. Therefore, the null hypothesis stating that "there is no significant relationship between the academic performance based on the Mean Grade of the first and second quarters of the student-respondents and their extent of computer literacy in terms of word processing," was rejected.

3.5.2. Spreadsheet. In associating the relationship between the academic performance of the student-respondents based on the Mean Grade of the first and second quarters and their extent of computer literacy in terms of spreadsheet using the Pearson's $r$, the computed value was posted at .697 denoting a "moderate" linear association. In testing the significance of the noted linear association between the two variables utilizing the Fisher's t-Test, the computed value was posted at 9.622 with df $=98$ and a $p$ value of .000 at $.05 \alpha$. The critical t-value was set at +1.984 . Furthermore, the computed value was compared with the critical value and the $p$-value was compared with the $\alpha$.

In the comparison of the aforementioned values, it was proven that the computed value turned greater than the critical value and the $p$-value turned lesser than the $\alpha$ thus the linear association between the two variables was significant which signified that the extent of computer literacy of the students in terms of spreadsheet did significantly influence their academic performance based on the Mean Grade of the first and second quarters. Therefore, the null hypothesis stating that, "there is no significant relationship between the academic performance based on the Mean Grade of the first and second quarters of the student-respondents and their extent of computer literacy in terms of spreadsheet," was rejected.

3.5.3. Presentation. In associating relationship between the academic performance of the student-respondents based on the Mean Grade of the first and second quarters and their extent of computer literacy in terms of presentation using the Pearson's $r$, the computed value was posted at .732 denoting a "moderate" linear association. In testing the significance of the noted linear association between the two variables utilizing the Fisher's t-Test, the computed value was posted at 10.636 with $\mathrm{df}=98$ and a $p$-value of .000 at $.05 \alpha$. The critical t-value was set at +1.984 . Furthermore, the computed value was compared with the critical value and the $p$-value was compared with the $\alpha$.

In the comparison of the aforementioned values, it was proven that the computed value turned greater than the critical value and the $p$-value turned lesser than the $\alpha$ thus, the linear association between the two variables was significant which signified that the extent of computer literacy of the students in terms of presentation did significantly influence their academic performance based on the Mean Grade of the first and second quarters. Therefore, the null hypothesis stating that, "there is no significant relationship between the academic performance based on the Mean Grade of the first and second quarters of the student-respondents and their extent of computer literacy in terms of presentation," was rejected.

3.5.4. General Computing. In associating relationship between the academic performance of the student-respondents based on the Mean Grade of the first and second quarters and their extent of computer literacy in terms of general computing using the Pearson's $r$, the computed value was posted at .741 denoting a "moderate" linear association. In testing the significance of the noted linear association between the two variables utilizing the Fisher's t-Test, the computed value was posted at 10.924 with df $=98$ and a $p$-value of .000 at $.05 \alpha$. The critical t-value was set at +1.984 . Furthermore, the computed value was compared with the critical value and the $p$-value was compared with the $\alpha$. 
In the comparison of the aforementioned values, it was proven that the computed value turned greater than the critical value and the $p$-value turned lesser than the $\alpha$ thus, the linear association between the two variables was significant which signified that the extent of computer literacy of the students in terms of general computing did significantly influence their academic performance based on the Mean Grade of the first and second quarters. Therefore, the null hypothesis stating that "there is no significant relationship between the academic performance based on the Mean Grade of the first and second quarters of the student-respondents and their extent of computer literacy in terms of general computing" was rejected.

In summary, the linear coefficients being positive suggested direct proportional relationships signifying that the students with greater extent of computer literacy in the identified areas manifested higher academic performance as shown by their mean grade during the first and second quarters than the students with a lower extent of computer literacy in all areas. This categorically implied that teachers should provide an intervention program that enhances the students' computer literacy in all said areas.

\subsection{Issues and Problems Encountered by the Student-Respondents Relative to Their Extent of Computer Literacy}

Table 12 reveals the issues and problems encountered by the student-respondents relative to their extent of computer literacy.

From the table, it can be noted that there were five identified issues encountered by the student-respondents relative to their extent of computer literacy. Out of these identified issues, they considered only one as "highly" encountered by them which corresponded to the statement stating, "use of computer, especially with internet connectivity leads one to access social media," with a weighted mean of 3.91. Moreover, this same group of respondents considered the remaining four issues as "moderately" encountered by them with weighted means ranging from 3.23 to 3.36. Corollarily, the issues that were rated with the highest and the least weighted means, respectively, corresponded to the statements stating: "dependency in computer slows down one's memory and calculation skills" and "computer eats up time and leads to non-productivity."

Taken as a whole, the student-respondents considered the issues relative to their extent of computer literacy as "moderately" encountered by them, being shown by the grand weighted mean of 3.42. This signified that the students felt some constraint with their computer literacy though in moderation. This hindered them from attaining full competency in computer operation and utilization. Thus, an intervention activity should be provided to minimize, if not eliminate, the issues they encountered relative to computer literacy.

Table 12: Issues and Problems Encountered by the Student-Respondents Relative to Their Extent of Computer Literacy

\begin{tabular}{l|c|c}
\hline \hline \multicolumn{1}{c|}{ Indicator } & $\begin{array}{c}\text { Weighted } \\
\text { Mean }\end{array}$ & Interpretation \\
\hline A. Issues & 3.35 & $\mathrm{M}$ \\
$\begin{array}{l}\text { 1. Use of computer makes one addicted to it. } \\
\text { 2. Use of computer leads one to indulge in computer games. } \\
\text { 3. Use of computer, especially with internet connectivity leads } \\
\quad \text { one to access social media. }\end{array}$ & 3.24 & $\mathrm{M}$ \\
4. Computer eats up time and leads to non-productivity. & 3.91 & $\mathrm{H}$ \\
5. Dependency in computer slows down one's memory and & 3.23 & $\mathrm{M}$ \\
\hline Galculation skills. & 3.36 & $\mathbf{3 . 4 2}$ \\
\hline Grand Weighted Mean & Moderately
\end{tabular}

\section{B. Problems}

6. Non-availability of computer units at home.

7. Stored files are prone to virus infection.

8. Using computer through internet cafes could be time consuming. 
9. Going to internet cafes after school with cause one to go home late.
2.24

3.29
S

10. Storing files from other computer inflects and corrupts existing files and makes them unreadable.
$\mathrm{M}$

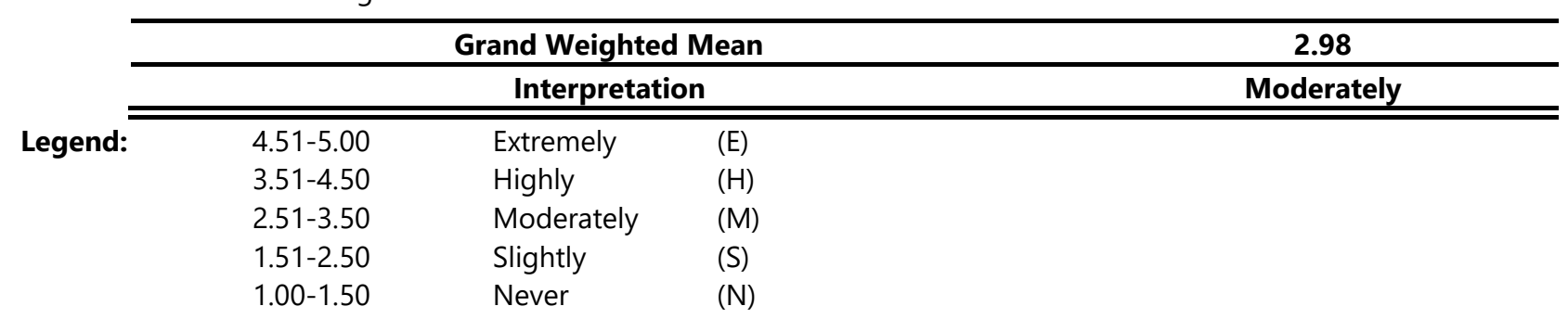

Furthermore, Table 12 also shows that there were five identified problems encountered by the student-respondents relative to their extent of computer literacy. The table further shows that this same group of respondents considered four identified problems as "moderately" encountered by them with weighted means ranging from 2.97 to 3.29. The identified problems which was rated with the highest and least weighted means, respectively, corresponded to the statement stating: "storing files from other computer inflects and corrupts existing files and makes them unreadable" and "stored files are prone to virus infection." The student-respondents considered the remaining identified problem as "slightly" encountered by them stating," going to internet cafes after school with cause one to go home late" with a weighted mean of 2.24.

Taken as a whole, the student-respondents considered the identified problems as "moderately" encountered by them relative to the extent of their computer literacy. This indicated that the students felt problems that hindered them from attaining the full extent of computer literacy. Although these problems were in moderation, it needs to be addressed properly to enhance the students' extent of competency regarding computer utilization and operation.

\subsection{Solutions to the Problems Encountered by the Student-Respondents Relative to Their Extent of Computer Literacy} Table 13 reflects the solutions to the problems encountered by the student-respondents relative to their extent of computer literacy. Five identified solutions were expected to address the problems encountered by the student-respondents.

The table shows that the student-respondents considered four identified solutions as "highly a solution" with weighted means ranging from 3.63 to 3.77 . The identified solution that obtained the highest weighted mean corresponding to the statement stating, "rent/use available computer at the internet cafes for research purposes" while the identified solutions that equally obtained least weighted mean stated: "regularly disinfect USBs to protect stored files" and "adopt time management when renting/using computer at the internet and be sure to be at home early." The remaining identified solution corresponding to the statement stating, "avoid using social media when renting computer in internet cafes as well as playing computer games" was rated by this same group of respondents as "moderately a solution" with a weighted mean of 3.37.

Table 13: Solutions to the Problems Encountered by the Student-Respondents Relative to Their Extent of Computer Literacy

\begin{tabular}{|c|c|c|c|}
\hline & Indicator & $\begin{array}{l}\text { Weighted } \\
\text { Mean }\end{array}$ & Interpretation \\
\hline 1. & $\begin{array}{l}\text { Rent/use available computer at the internet cafes for research } \\
\text { purposes. }\end{array}$ & 3.77 & HS \\
\hline 2. & Disinfect regularly USBs to protect stored files. & 3.63 & HS \\
\hline 3. & $\begin{array}{l}\text { Adopt time management when renting/using computer at the } \\
\text { internet and be sure to be at home early. }\end{array}$ & 3.63 & HS \\
\hline 4. & $\begin{array}{l}\text { Avoid using social media when renting computer in internet cafes } \\
\text { as well as playing computer games. }\end{array}$ & 3.37 & MS \\
\hline 5. & Be sure to back up files for safety. & 3.74 & HS \\
\hline & Grand Weighted Mean & \multicolumn{2}{|c|}{3.63} \\
\hline & Interpretation & \multicolumn{2}{|c|}{ Highly a Solution } \\
\hline & $\begin{array}{l}\text { Extremely a Solution } \\
\text { Highly a Solution }(\mathrm{HS})\end{array}$ & & \\
\hline
\end{tabular}




$\begin{array}{lll}2.51-3.50 & \text { Moderately a Solution } & \text { (MS) } \\ 1.51-2.50 & \text { Slightly a Solution } & \text { (SS) } \\ 1.00-1.50 & \text { Not a Solution } & \text { (NS) }\end{array}$

Taken as a whole, the student-respondents considered the identified solutions as "highly a solution" being indicated by the grand weighted mean of 3.63. This signified that the students felt that the identified solution would address the encountered problems relative to their computer literacy. Impliedly, these solutions should be considered in the intervention activity that the teachers will provide for the students to enhance their competence in computer operation and utilization.

\section{Conclusion}

The students manifested a highly favorable attitude toward computer which implied their interest in learning it. However, they still felt the need to enhance their computer literacy in the areas of word processing, spreadsheet, presentation, and general computing. Thus, teachers should support them by providing intervention activities to improve their computer literacy level in the identified areas. The extent of their computer literacy in word processing significantly differed in their interest in computer. In the spreadsheet, it was essentially similar, while in the presentation, it was essentially similar irrespective of the disparity when paired according to their attitude toward computer. Lastly, in general computing, it also significantly differed in their attitude toward computer.

Moreover, students showed a favorable performance higher than the required 75 percent mastery level set by DepEd. All areas considered in their computer literacy significantly influenced their academic performance based on their mean grades during the first and second quarters in a directly proportional manner. This signified that the higher their computer literacy in the identified areas manifested, the higher the academic performance also. Hence, an intervention program is imperative to enhance the extent of the students' computer literacy, especially that they felt some constraints with it. Thus, this should be addressed properly through an intervention program to minimize, if not eliminate, the issues and problems they encountered relative to computer literacy.

\section{References}

[1] Aitokhuehi, J.O. \& Ojogho, J. (2014). The Impact of Computer Literacy on Students' Academic Performance in Senior Secondary Schools in Esan West Local Government Area, Edo State, Nigeria. Journal of Education and Human Development, 3(3)

[2] Cohen, A. (2010). Characteristics of effective mobile learning. Retrieved from http://www.brainscape.com/blog/2010/09/characteristics-ofeffective-mobile-learning/ 32 Fawareh H. M. A., Jusoh, S. (2017). The Use and Effects of Smartphones in Higher Education. IJIM (11), 6.

[3] Department of Education. (2011). https://www.deped.gov.ph/2011/06/01/do-46-s-2011-revised-guidelines-on-the-implementation-of-thedeped-internet-connectivity-project-dicp/

[4] Jarvis, H., \& Pastuszka, L. (2008). Electronic literacy, reading skills and non-native speakers: issues for EAP. CALL-EJ Online, 10(1). Retrieved from http://callej.org/journal/10-1/jarvis.html

[5] Leonard, K. (2019). The Advantages of Being Computer Literate in the Workforce. https://smallbusiness.chron.com/advantages-beingcomputer-literate-workforce-27703.html

[6] MathGenie. (2018). The Danger of Computer Illiteracy in an Increasingly Digital. Worldhttps://www.mathgenie.com/blog/the-danger-ofcomputer-illiteracy-in-an-increasingly-digital-world

[7] Mbaeze, I. C., Ukwandu, E., \& Anudu, C. (2010). The influence of information and communication technologies on students' academic performance. Journal of Information Technology Impact, 10(3), 129-136. Available from https://www.researchgate.Net/publication/272179181The_Influence_of_Information_and_Communication_Technologies on Students' Academic Performance

[8] Reynolds, N. J. (2008). An Ecological Approach to ICT and Children. In: Benzie, D., Zammit, K. (eds.) IFIP WG 3.5 International Conference - Valuing individual and shared learning: the role of ICT. Charles University in Prague, Czech Republic. 